\title{
PDGFRB Protein Variant
}

National Cancer Institute

\section{Source}

National Cancer Institute. PDGFRB Protein Variant. NCI Thesaurus. Code C128173.

A variation in the amino acid sequence of the platelet-derived growth factor receptor beta protein. 